Article

\title{
Does Bilingual Instruction Impact Students' Academic Performance in Content-Based Learning? Evidence from Business School Students Attending Bilingual and L1 Courses
}

\author{
Teng Lin ${ }^{1, *}$ and Yuanyue $\mathrm{He}^{2}$ \\ 1 School of Accounting, Guangdong University of Foreign Studies, Guangzhou 510006, China \\ 2 English Language Center, Shantou University, Shantou 515063, China; shawnahe@stu.edu.cn \\ * Correspondence: linpt@gdufs.edu.cn; Tel.: +86-20-3932-8957
}

Received: 6 December 2018; Accepted: 30 December 2018; Published: 7 January 2019

check for updates

\begin{abstract}
Despite the rapid adoption of bilingual programs (English-Chinese) in Chinese higher education institutions (HEIs), concerns have been raised about perceived language hindrance to students' academic comprehension and performance. In response to these concerns, we investigated the effects of bilingual instruction on content-based learning, and provide empirical evidence after testing influential factors in bilingual environments. Analyzing a sample of 498 undergraduate students enrolled in a fundamental business course at a sample university in China, we found insignificant statistical differences in the students' academic performance between bilingual and L1 (Chinese) classes. We attribute this to the English language support provided by the university, and show that learning competence can help students minimize language barriers and solve common learning problems facing both bilingual and L1 students. Overall, our paper aimed to identify key determinants of students' academic performance during bilingual instruction, and provide policy implications for developing desirable bilingual programs in HEIs.
\end{abstract}

Keywords: bilingual program; academic performance; learning competence; English proficiency; student workload

\section{Introduction}

The English language has been used extensively in Chinese universities, including 985 and 211 (985 and 211 are the fundamental classifications of Chinese universities. Normally, the top 100 universities are the 985 and 211 universities in China. Please refer to "International Rankings and Chinese Higher Education Reform" World Education News and Reviews. http://en.wikipedia.org/wiki/Project_985 Retrieved 20 August 2012 and https://en.wikipedia.org/wiki/Project_211) Universities, since the opening-up reform in the 1990s [1]. The purpose of promoting the use of English in Chinese higher education is many-fold; internationalizing institutions (Altbach and Knight [2]; Huang [3]; Kim et al. [4]), and increasing competitiveness in the global context (Coleman [5], Deem et al. [6] and Costa and Coleman [7]). Dobrota et al. [8] showed that the adoption of English can enhance a university's global ranking, and attract international talent and students. English proficiency at the tertiary level is regarded as a national and personal achievement (Adamson [9], Hu [10]; Jin and Cortazzi [11]). In 2004, China's Ministry of National Education published the No. 4 Notice titled "Opinion on Further Strengthening the Undergraduate Teaching" (http:/ / www.moe.edu.cn/publicfiles/business/htmlfiles/moe/moe_734/ $200507 / 8296 . \mathrm{html})$, advocating the need for English intermediate-level education at university and college levels. Following the No. 4 Notice, the Bureau of Education in Shanghai City (SHC) specifically pointed out that colleges and universities in SHC should actively support bilingual (Chinese and English) 
education and set the target of $10 \%$ courses/subjects to be conducted bilingually by the end of 2004 . Nowadays, students in many Chinese universities can find non-language-learning courses taught bilingually. Additionally, a few courses are even conducted completely in English (Shi [12]).

After reviewing previous literature, we observed that limited empirical research has been directed at the bilingual impact of understanding subject content, despite one known criticism of bilingual instruction that is students' adequate comprehension. We linked the lack of research in the area to a number of reasons. First, empirical research in this area needs perspectives from cross-disciplinary groups and settings beyond language issues. To the best of our knowledge, only a few researchers have integrated cross-disciplinary studies to jointly examine the language impacts on non-language content teaching and learning. Second, as suggested by Dafouz et al. [13], there is a lack of standardized content exams facilitating comparative analysis. It is not easy to analyze how language instruction impacts different forms of examination. Third, the confidentiality associated with students' grades minimizes the data available for empirical research. This limitation constrains researchers performing empirical research at a country or multi-institutional levels. Finally, as stated by Fortanet-Gomez [14] and cited by Dafouz and Camacho [15], a conceived political or ideological bias may exist, since many researchers favor negative results, especially as academic achievements do not emerge from English-medium instruction (EMI) programs. Criticisms arise from concerns about student's language proficiency and participation in the class (Wang [16], Sert [17], Byun et al. [18]), instructors' qualification (Wang [16], Li [19], Crawford and Wang [20]), rapid increase in teaching load (Van Der Walt [21], De Courcy [22]), and lack of university-level support (Yang and Gosling [23]). In response to these issues, we attempted to examine the effects of bilingual instruction on students' academic performance, and provide empirical evidence of determinant factors in the bilingual and native language environments.

In addition, our study had the following specific objectives: (1) to statistically investigate the impacts of bilingual instruction on the students' academic achievements in a specific area that offers parallel L1 instruction for comparison; (2) to examine the effectiveness of bilingual education and present valid empirical evidence on influencing factors, which provides feasible implications for students' learning achievement, teachers' pedagogical preparation, and universities' management support in bilingual cases; and (3) to provide a fresh model for exploring effective learning conditions for bilingual instruction and reflective thoughts for policy makers to plan the future development of bilingual programs in Chinese Higher Education Institutes (HEIs). Bilingual education is a gateway to sustainable development in an environment where English and local languages are used simultaneously. The benefits of adopting bilingual education are profound for the learners who aim to have a sustainable development in their career which demands bilingual practices in their workplace (Defouz and Camacho [15]).

The rest of the paper is organized as follows. Section 2 provides a literature review and develops our research questions. Section 3 discusses our sample selection, data collection, models, and the measurement of variables. Section 4 presents the empirical results, discussions, and sensitivity tests. Finally, the conclusions are presented in Section 5.

\section{Literature Review and Research Question}

Much research on L2 impacts has been conducted in the European context, especially in Spain, Sweden, Denmark, and Austria, where L2 is English. Some researchers examined the L2 language policy and its impacts in some countries in the Asian regions, such as Korea, Taiwan, Hong Kong, etc. However, findings from these studies suggest that the impact of L2 on students' academic performance remains inconclusive (Dafouz and Camacho [15]). Research shows that L2 students have language difficulties during the learning process, and therefore may have lower academic performance as found in the Turkish (Sert [17]) and Korean (Byun et al. [18]) contexts. Sert [18] reported that students may find it hard to comprehend subject content clearly, which may prevent them from developing critical thinking abilities. Byun et al. [18] argued that the compulsory adoption of English-Medium Instruction (EMI) in Korea seems to lack the much-needed support system and appropriate lecturers; therefore, 
the overall implementation of EMI across academic disciplines indicates that it can hinder student's comprehension of the teaching content. A meta-analysis conducted by Lo and Lo [24] revealed that, unlike EMI programs in other educational contexts (e.g., Canada or Europe), in Hong Kong it may cause a failure in academic achievement due to the students' insufficient language training and deficiency in teachers' pedagogical skills. Conversely, a number of studies found that insignificant differences exist in the academic performance of L1 and EMI students. A study by Dafouz and Camacho [15] used two groups of accounting students engaged in EMI and L1 (Spanish) classes. A total of 383 students' grades were collected and compared using mean difference tests. The results showed no statistical differences across groups. Similar results of insignificant differences were also reported in Dafouz et al.'s [13] study of three first-year subjects (Economic History, Financial Accounting, and Finance). Their work indicates that difficulties in EMI learning were also experienced by L1 students, who were mostly in the process of developing academic literacy. L2 students have ease of access to authentic materials (Bergroth [25]) and show positive attitudes toward bilingual learning (Tong and Shi [26]). Their academic subjects' learning outcome has been found not to be adversely affected.

The increasing use of English in China's university programs has received critical reviews from participants and policy makers (Hu [27], Hu and Lei [28]). A handful of research in the Chinese setting, documents that EMI is of benefit to students' English skills and subject knowledge. For instance, as cited from Guo et al. [29], Yan and Xu [30] report that students achieve higher scores in the content learnings and English proficiency tests after attending EMI courses. A recent study by Guo et al. [30] finds that EMI and Chinese-medium instruction (CMI) students performed on par in their final exams in the subject, suggesting that EMI did not necessarily carry a hindering effect on Chinese college students' content learning. Tracking theoretical and practical issues of EMI, Zhao and Dixon [31] discuss the legitimacy of promoting EMI in Chinese universities and the sociolinguistic consequences of EMI on Chinese language and culture. The issues on the adoption of EMI for students with different levels of English proficiency, and different subjects have not been fully addressed. Evidence of the transition for EMI instructors from teaching their academic discipline in their first language to teaching through their second language (English) is limited. Therefore, Zhao and Dixon [31] propose research opportunities for testing the quality and effectiveness of EMI courses that are highly related to the students learning outcomes.

\subsection{Chinese Bilingual Education}

English and other European languages (French, German, Dutch, Swedish, etc.), are closer than English and Chinese (Pérez-Cañado [32]). In European countries, bilingual (L1 and English) instruction is usually carried out in secondary schools, and EMI (L2) courses are provided at the higher education institutions (HEIs) level. Considering the significant differences between Chinese and English language families (Janson [33]), bilingual instruction is more popular than EMI in Chinese HEIs because it provides transitional language support to Chinese students in the L2 environment. There are four main types of bilingual models in China: (i) foreign language teaching in mainstream education; (ii) maintenance bilingual instruction; (iii) transitional bilingual instruction; and (iv) immersion bilingual instruction (Hu [34], Tong and Shi [26]). Bilingual courses in the mainstream Chinese Business School adopt a transitional bilingual model. Following decades of reforms by the government and educators, bilingual instruction is unique in the Chinese higher education system. Bilingual courses are usually conducted by mainly lecturing in Chinese in the classroom, and using teaching material, such as textbooks, presentation notes, exercises, and examinations in English.

Though no organized longitudinal research has been conducted to investigate the academic accomplishment of learning non-language subjects in English, there are already some suggestions that the use of English in bilingual programs may negatively affect students' academic performance, as suggested in Hu's critical review [27]. Shen [35] admitted that bilingual education may "injure subject learning" and requires strategies to address these drawbacks. Some Chinese bilingual instructors have complained about reducing or simplifying curricular content to enable students, 
with inadequate language competence, to understand the complex topics in English (Pi [36]). Another report by Jin and Zhuang [37] stated that the instructors have to teach major topics in Chinese again after half a semester of bilingual instruction, because the students achieved poor performance in assessments. While analyzing the institutional background and implication of bilingual education in the Chinese higher education system, Wang [16] suggested that bilingual education is not applicable to all subjects and course studies. For Chinese students, courses and subjects related to Chinese tradition and unique character are not recommended to be bilingually conducted. Li [38] (The university used in $\mathrm{Li}$ (2016) is in Northwestern China where the students' overall English proficiency level is below average compared to the southeastern coastal areas. Therefore, Li indicated that results may not be generalized to other Chinese universities, high;ighting a research opportunity for investigating bilingual program effectiveness in areas with students having high English proficiency.) examined the effectiveness of a bilingual program in social science majors at a Chinese tertiary level, and highlighted that the mastery of subject knowledge in the bilingual model is questionable. In a transition period to bilingual education, Shi [12] found diverse performance in bilingual education between developed and underdeveloped areas in China. Regardless of the milestone accomplishment achieved by the tertiary institutions in China's top tier cities, such as those in Beijing and Shanghai, further improvement and efforts are needed for students in underdeveloped areas, such as inland and western regions. To prepare Chinese students well in the L2 environment, many Chinese universities provide language support facilities and courses. As demonstrated in previous literature, there is an inconclusive impact of language instruction (mainly L1 and EMI) on students' academic performance; we were therefore motivated to find new empirical evidence in bilingual instruction in this setting. Therefore, our first research question (RQ1) is: Does bilingual instruction impact students' academic performance compared to L1 instruction?

\subsection{English Proficiency}

From a linguistics perspective, the concept of language proficiency and how it can be measured accurately has been controversial for decades (Cummins [39]). Cummins distinguished language proficiency into cognitive/academic language proficiency (CALP), and Basic interpersonal communicative skills (BICS). CALP is defined as those aspects of language proficiency which are closely related to the development of literacy skills in L1 and L2. BICS in L1 such as accent, oral fluency, and sociolinguistic competence may be independent of CALP for a variety of reasons (Cummins [39], p. 177). In the domain of bilingual education, Cummins [40] conceptualized a Threshold Hypothesis (TH) and stated that, "the level of linguistic competence attained by bilingual children may act as an intervening variable in mediating the effects of bilingualism on their cognitive and academic development" (p. 232). According to Cummins [40], students with low levels in both L1 and L2 ("semilingualism") who fail to interact with their educational environments may experience certain disadvantages of academic achievement. For students with native-like level in either language ("dominant bilingualism"), there are no longer positive or negative cognitive effects on their bilingual competence; and students with high levels in both languages ("additive bilingualism") are likely to enjoy cognitive and academic advantages. To revisit the TH, a study conducted by Ardasheva et al. [41], using a sample of 18,528 language learners at different levels, examined the possible impact of English proficiency levels on academic achievement of middle school students. The result showed that upon reaching an adequate English level, English language learners (ELLs) no longer suffer academic disadvantages. Other evidence found by Hamzah et al. [42] revealed that there is a significant direct effect of English proficiency on academic achievement, suggesting that more activities geared toward increasing students' language proficiency may be necessary. ELLs are expected to experience more academic language support that facilitates their content learning (Lin and Zhang [43]). Dong and $\mathrm{Du}$ [44] conducted a survey on the relationship between Chinese students' academic performance and their China National College English Test (CET) scores. The CET is designed to test non-English-major students' general English ability in listening, speaking, reading comprehension, 
and writing. Its purpose is to ensure that students meet the required English levels specified in the National College English Teaching Syllabuses (NCETS). The CET has been used in China for more than two decades and now has a huge test population of 18 million people annually as cited from CET's official website.

Dong and Du [40] uncovered a significant correlation between CET scores and academic performance in bilingual education. Similarly, an empirical study (Han and Yu, [45]) exploring requisite English skills for bilingual education among Chinese university students suggests that students can benefit from bilingual education when they achieve excellent scores in CET4 or CET6. For college students in bilingual education, new reflections by Cummins [46] indicated that older school-age students progress faster than younger students (e.g., students in kindergartens or junior schools) in acquiring L2 academic proficiency, because they can apply their better-developed cognitive/academic language proficiency to L2 learning. Bilingual instruction also brings social benefits, so students are likely to be more motivated when speaking to native speakers and develop more positive attitudes toward L2 (Lasagabaster and Sierra [47], Merisuo-Storm [48]). Based on the research, English proficiency has been identified as a key dominant predictor of academic performance. Dedicated to developing students' communicative competence and critical thinking, the sample university in this study provides them an intellectual English learning environment, which is more beneficial to students being committed to bilingualism. In this unique bilingual teaching environment, we were motivated to propose the second research question (RQ2): Does English proficiency play a fundamental role in students' academic performance in a bilingual environment?

\subsection{Learning Competence}

In addition to English proficiency, we perceive learning competence as another key decisive determinant of students' academic achievements. Ning and Downing [49] measured learning competence using the Learning and Study Strategies Inventory (LASSI, Weinstein and Palmer [50]), and found a positive relationship between academic performance and learning competence. Students are motivated to change their learning strategy to address difficulties in the L2 environment. For example, Tatzl [51] presented the results of a questionnaire survey on students' attitudes, experience, and challenges in the Austrian context. The survey analysis showed that students recognize and tackle the challenges in EMI courses. Similarly, Airey and Linder [52] and Airey [53] found that L2 students can adjust their learning strategy to deal with language problems, such as reading the pre-lecture section and reducing note-taking to listen intensively. Learning fundamental terminology and vocabulary in a subject is equally important in L1 or EMI courses. Therefore, junior students, regardless of L1 or L2, need to build a concept and theoretical framework that will lead to application in the advanced level. Hellekjaer [54], using a sample of 391 respondents in L1 and L2 (English) instruction at three Norwegian HEIs, found that lecture comprehension problems in the L2 environment were similarly found in students in the L1 environment. These common problems were connected to the discipline's specific vocabulary and the process of socializing students into domain-specific academic genres, and registers with specific vocabularies (Hellekjaer [54], p. 248). For students to succeed in academic learning, their learning competence is also a decisive factor in tackling these common comprehensive problems in their junior level (for example, see Basturkmen and Shackleford [55] in accounting discipline research and Klaassen [56] in an engineering case). Therefore, we propose the third research question (RQ3): Can learning competence minimize language hindering of students' academic performance in a bilingual environment?

\section{Research Methodology}

\subsection{Sample and Setting}

The sample included undergraduate students (second semester of first-year study) participating in the core course Fundamental Accounting (BUS1004A) in a Chinese university's business school, 
in the 2015 academic year. The business school was set up in 1996, with 61 full-time faculty and 2269 students in the main campus in 2016. Its Business Administration program received the Well-Known Program Award from the Guangdong Provincial Education Department in 2006, and the Distinctive Program Award from China's Ministry of Education (MOE) in 2007. In 2012, its Bachelor of Business Administration was accredited by the European Foundation for Management Development (EFMD) Program Accreditation System (EPAS). In 2015, all undergraduate programs passed the EPAS assessment and won international accreditation. The university has established international cooperation and exchange programs with 56 partner universities from 16 countries/regions, including Hong Kong, USA, Canada, and many European countries, providing students with the opportunity to travel abroad for studies and exchange programs. There are 45 compulsory courses provided by the business school. Among them, 23 courses are conducted bilingually, and nine courses are taught completely in English (L2) by international faculties. Due to the EPAS accreditation and increasing use of English as course language, students in the exchange programs can receive credit recognitions and transfers between associated universities and the international partner institutions.

The sample course offers parallel bilingual and L1 (Chinese) sessions. Bilingual sessions use English version material, while L1 sessions adopt Chinese version material. The syllabus, textbooks, course material, and exam papers used in both sessions are the same in content and translated interchangeably. In a bilingual class, the instructor mainly uses L1 (Chinese) in lectures and interactions. The sample business school has commenced bilingual classes to comply with the national policy of strengthening undergraduate teaching advocated by the MOE since 2004. Currently, more than half of the compulsory courses in the Business School provide bilingual sessions. The university has set rigid qualification requirements in the bilingual teaching environment. To qualify as a bilingual instructor, an instructor (The purpose of bilingual teaching qualification guidance is to demand candidates achieve the required level of English competence and qualification in content teaching.) should have met the following criteria: (1) a thesis-based degree written and presented in English; (2) have experience in successfully publishing a paper in English in an international journal as a first author or a corresponding author; (3) have attended an international conference and presented a paper/outcome; and (4) a PhD degree.

The sample university has a well-established English Language Centre (ELC) initiated by the National Writing Project at the University of California, Berkeley, USA and commissioned by the $\mathrm{Li}$ Ka Shing Foundation in 2002. Over the past few years, the university has distinguished itself from other universities in China under ELC sponsorship, which recruits half of its faculty from abroad. With the specialized mission of improving students' English language proficiency, learning autonomy and sustainability, intercultural competence, and critical thinking, ELC has taken on the responsibilities of English teaching for the entire campus community (about 7000 students), including English-major students and graduate students, within the newly designed curriculum of the university's credit-bearing system. Regarding the accounting discipline, the transformation to bilingual teaching and learning is challenging due to internationalization of Chinese financial accounting standards and its convergence with International Financial Reporting Standards (IFRS), which is published in English. Many universities, especially the 985 and 211 ones, are motivated to provide bilingual accounting courses to meet the needs of employment (He, [57]). However, the question of whether bilingual courses can equip students with an equal knowledge foundation compared with L1 courses remains unsolved.

Accounting is a basic subject for completing a business-related degree; however, many business students consider accounting the most difficult fundamental subject required by the business school (Dafouz and Camacho [15]). Like many other academic subjects, accounting has its own vocabulary and language style that students need to understand, to learn the subject in depth and apply it into their future profession (Basturkmen and Shackleford [55]). Kieso et al. [58] defined accounting as identifying, measuring, and communicating financial information about economic entities to interested users. The objective of accounting is to provide useful information to various 
users for decision making. Due to the convergence between the Chinese Financial Accounting Standards (CFAS) and International Financial Reporting Standards (IFRS) in 2007, China's basic framework and definitions of key concepts and elements are translated between the Chinese and English languages (https://www.iasplus.com/en/jurisdictions/asia/china IAS Plus features an extensive collection of news and resources about International Financial Reporting Standards (IFRS), the International Accounting Standards Board (IASB), and international accounting and auditing developments.). The convergence of the global accounting standards is beneficial to many global investors, with investments in different nations because the comparability, consistency, and readability of the financial statement across countries have been improved under a common global accounting framework. With the influence of internationalization in China's tertiary institutions, all top tier universities in China develop bilingual accounting courses to prepare accounting students for the job market needs. Students can either choose L1 or the parallel bilingual course depending on their career goal and interests.

The accounting course offers parallel Bilingual and Chinese (L1) classes in the same semester. Following the universities policy to maintain consistency, both classes use the same teaching material that is equivalently and consistently translated between English and Chinese (L1 classes use the Chinese material, while bilingual classes use the English material. Please refer to Research Methodology section for more explanation of teaching material.) (i.e., syllabus, textbooks, homework, presentations, and exam papers). Kuteeva and Airey [59] argued that educational policies should take fundamental disciplinary differences into consideration when adopting English (L2) as the medium of instruction. Accounting is a fundamental subject for students to meet the Business Administration program requirements or to acquire an economics degree at a business school. Before selecting the sessions, students are required to take examinations in the English Language Centre (ELC) to determine their English proficiency level. Based on Chang et al.'s studies [60], one solution to the hindering the effects of $\mathrm{L} 2$ is to provide supportive learning conditions and language assistance programs. Therefore, the ELC at the sample university provides academic language supports in reading, writing, and listening to students enrolling in bilingual courses. The syllabus, textbooks (There are two major publishers in China, namely China Machines Press (http:/ / cmpbook.emie.com.cn) and Northeastern University of Finance and Economic Press (http://www.dufep.cn/), providing the translated (English-Chinese) version of the mainstream textbooks for the Business School in China.), presentation notes, and exam papers used in the bilingual and L1 programs are literally translated between the two languages. We collected the whole sample of 520 students enrolling in these two sessions, 196 bilingual and 324 L1 students, respectively. However, 12 of the students did not meet the CET6 test requirements, an important variable for controlling students' English proficiency level. Four of them missed the assessment due to absences and six did not satisfy the control variables. After dropping the 22 students with missing values, we had a final sample of 498 . We further divided the students into groups based on their major being Business Administration, resulting in 118 accounting major students and 380 non-accounting major students, such as finance and marketing students. The course instructors were qualified and experienced lecturers/professors who have taught accounting subjects for many years. In addition to Fundamental Accounting, they also teach courses titled Financial Statement Analysis, Intermediate Accounting, Auditing, International Accounting, etc.

\subsection{Empirical Model}

We used multiple regression analysis to test the impact of language of instruction on students' academic performance, and controlled the effects of students' English proficiency level, learning competence, and other important factors. As a statistical tool, multiple regression offers flexibility and adaptability to facilitate testing a large number of independent and dependent variables. The regression model is presented as below: 
Academic Performance ${ }_{i}=\beta_{0}+\beta_{1}$ Language Medium $_{i}+\beta_{2}$ English Proficiency $_{i}$

$+\beta_{3}$ Learning Competence $_{i}+\beta_{4}{\text { Student } \text { Workload }_{i}+\varepsilon_{i}}$

where Academic Performance is a dependent variable derived from the result of class performance (30\%), homework (20\%), and paper-based examination results (50\%). Following the guidelines set by the University's assessment policy (Shantou University Document 2016 No.78: Management Regulation of Course Assessment (11ed). According to university regulations, the Business School has introduced "Core Assessment Question Form" process to core/mandatory courses. The faculty members need to present core questions in the final exam, key component of the answer to the core question and evaluation standards. After assessment, faculty members are required to submit the "Continuous Improvement Form" to indicate student's achievement against the program learning objectives and area of improvement.), the course has various closely linked assessment questions to course learning objectives. All teaching materials (Chinese/English) and assessments were standardized to cover core learning objectives. Exam papers are cross-examined by the L1 and bilingual instructors to maintain marking consistency. L1 exams are Chinese-based and bilingual exams use English as a medium. A score of 100 (For many universities in China, students' academic score is recorded using the centesimal or the hundred-mark system in which a score value ranges from one to one hundred marks.) represents full mark and any score lower than 60 is considered a failing mark. Language Medium is a dummy variable of one if the course is bilingual, and zero is L1 conducted. We have other control and independent variables controlling the students' English level (Kim et al. [4]), learning competence (Ning and Downing [49]), and student workload (Van der Meer et al. [61]). First, for students enrolling in the bilingual courses, English proficiency is a key determining factor of their academic performance because the course material and assignments are all in English. It is highly expected that higher English proficiency can help students understand subjects in English better and quicker. Student English proficiency was proxied by the CET4 and CET6 scores. Secondly, learning competence is another critical variable that is positively related to academic performance as suggested by Ning and Downing [49]; therefore, we measured learning competence using the proxy of Grade Point Average (GPA). Third, student workload is a controversial factor influencing academic performance (Szafran [62]). In this study, we used the number of credit hours as a proxy of workload. The detailed definition of the variables is presented in Appendix A.

\section{Results and Discussion}

\subsection{Descriptive Statistics}

This section provides the descriptive statistics of students' academic performance, class type, and control variables such as GPA score, English proficiency, and study load. Through these descriptive statistics, students' performance and characteristics were reported and compared in different class sections. Table 1 shows the whole sample's statistics of Score with a minimum of 46 and maximum of 92.5. Score is the comprehensive result of Score1 and Score2, representing students' exams score and class performance, respectively. In total, 187 students attended bilingual classes, accounting for $37.55 \%$ of the total enrollment. We then had 311 students attending L1 classes. On average, students participated in 24 credit hours in the semester with a maximum of $25 \mathrm{~h}$ and a minimum of $21 \mathrm{~h}$. Credit hour was used to measure students' workload as we assumed that students with lower study load may have more time to spend on the course. The average scores of CET4 and CET6 in the whole sample were 519.97 and 470.93 , respectively. The sample university's CET performance was ranked 28th in China and fifth in Guangdong Province in year 2015. Furthermore, 25\% of students were enrolled in an accounting major. Table 1 also provides the descriptive statistics for the L1 and bilingual classes. Bilingual students had fewer credit hours and workload than L1 students. This may suggest that bilingual students can allocate more time to a subject than their counterparts. The results show students in bilingual classes were associated with higher GPA, CET4, and CET6 averages. 
Table 1. Descriptive statistics for the sample.

\begin{tabular}{|c|c|c|c|c|c|}
\hline \multicolumn{6}{|c|}{ (1) The Whole Sample Including Both L1 (Chinese) and Bilingual Classes } \\
\hline Variable & $n$ & Mean & SD & Min. & Max. \\
\hline Score & 498 & 77.584 & 10.451 & 46.000 & 92.500 \\
\hline Bilingual & 498 & 0.376 & 0.485 & 0 & 1 \\
\hline GPA & 498 & 3.253 & 0.457 & 1.480 & 3.915 \\
\hline Credit Hours & 498 & 23.974 & 2.315 & 9.000 & 25.000 \\
\hline GAS & 498 & 82.296 & 5.078 & 57.870 & 89.180 \\
\hline GBS & 498 & 74.758 & 4.673 & 52.217 & 82.290 \\
\hline CET4 & 498 & 519.973 & 49.002 & 298.000 & 599.500 \\
\hline CET6 & 498 & 470.930 & 33.862 & 317.000 & 539.500 \\
\hline Accounting Major & 498 & 0.237 & 0.426 & 0 & 1 \\
\hline \multicolumn{6}{|c|}{ (2) The Sample of L1 (Chinese) Class Only } \\
\hline Variable & $n$ & Mean & SD & Min. & Max. \\
\hline Score & 311 & 77.823 & 10.438 & 47.000 & 92.500 \\
\hline Bilingual & 311 & 0 & 0 & 0 & 0 \\
\hline GPA & 311 & 3.240 & 0.445 & 1.480 & 3.915 \\
\hline Credit Hours & 311 & 24.093 & 2.125 & 9.000 & 25.000 \\
\hline CET4 & 311 & 517.754 & 47.954 & 389.000 & 599.500 \\
\hline CET6 & 311 & 469.510 & 35.12 .8258 & 317.000 & 539.500 \\
\hline Accounting Major & 311 & 0.232 & 0.422 & 0 & 1 \\
\hline \multicolumn{6}{|c|}{ (3) The Sample of Bilingual Class Only } \\
\hline Score & 187 & 77.187 & 10.488 & 46.000 & 92.500 \\
\hline Bilingual & 187 & 1 & 0 & 1 & 1 \\
\hline GPA & 187 & 3.274 & 0.476 & 1.480 & 3.915 \\
\hline Credit Hours & 187 & 23.775 & 2.593 & 9.000 & 25.000 \\
\hline CET4 & 187 & 523.663 & 50.611 & 298.000 & 599.500 \\
\hline CET6 & 187 & 473.300 & 37.610 & 345.000 & 539.500 \\
\hline Accounting Major & 187 & 0.246 & 0.432 & 0 & 1 \\
\hline Variable & \multicolumn{5}{|c|}{ Definition } \\
\hline Score & \multicolumn{5}{|c|}{$\begin{array}{l}\text { The comprehensive results including class attendance rate, home assignments, } \\
\text { and paper-based examination result. }\end{array}$} \\
\hline Score1 & \multicolumn{5}{|c|}{ The student's paper-based exams result. } \\
\hline Score2 & \multicolumn{5}{|c|}{$\begin{array}{l}\text { The student's class performance score, which is a combination score of class participation, } \\
\text { attendance, and in-class quiz results. }\end{array}$} \\
\hline Bilingual & \multicolumn{5}{|c|}{ A dummy variable of 1 if the course is bilingual and 0 if $\mathrm{L} 1}$. \\
\hline GPA & \multicolumn{5}{|c|}{ The grade point average used to measure student academic achievement. } \\
\hline Credit Hours & \multicolumn{5}{|c|}{$\begin{array}{l}\text { The total study time that students spend on the course during a semester, also used to } \\
\text { measure students' workload. }\end{array}$} \\
\hline GAS & \multicolumn{5}{|c|}{$\begin{array}{l}\text { A modified GPA score used to control workload impact. For example, two students } \\
\text { studying the same course with different workloads receive the same academic result. } \\
\text { The students with higher workload are considered to have higher GAS under its } \\
\text { calculation formula. }\end{array}$} \\
\hline GBS & \multicolumn{5}{|c|}{ A modified GPA score to control for the effects of English proficiency. } \\
\hline CET4 & \multicolumn{5}{|c|}{$\begin{array}{l}\text { CET } 4 \text { is the basic level of CET. CET stands for China National College English Test and is } \\
\text { designed to test non-English-Major students' general English ability in listening, speaking, } \\
\text { reading comprehension and writing. Its purpose is to ensure that students meet the } \\
\text { required English levels specified in the National College English Teaching Syllabuses } \\
\text { (NCETS). CET haves been operated in China for more than two decades and now has a test } \\
\text { population of } 18 \text { million people annually (http://www.cet.edu.cn/). }\end{array}$} \\
\hline CET6 & \multicolumn{5}{|c|}{ CET 6 is the advanced level of CET. } \\
\hline Accounting Major & \multicolumn{5}{|c|}{ A dummy variable of 1 if students major in accounting and 0 otherwise. } \\
\hline
\end{tabular}

\subsection{Main Result}

Table 2 presents the ordinary least regression (OLS) results of testing the relation between academic performance proxied by Score and bilingual instruction proxied by Bilingual. Overall, the results 
show the consistent and insignificant association between Score and Bilingual in different models. Linking the insignificant result to RQ1 (Does bilingual instruction have impacts on students' academic performance compared to L1 instruction?), bilingual students were not necessarily associated with weaker academic performance. Similarly, a recent paper by Watzinger-Tharp [63] suggested that dual language immersion (DLI) students performed at the same level as their non-DLI peers in tests given in English. We tested the sample using the empirical model in Equation (1). Different variables were added or removed from the regression equation to test the different effects in different models. For example, in Model (1) of Table 2, Bilingual, CET4 regressed on Score to showing a relationship between them. Models (1) and (2) demonstrated the insignificant association with the control of English proficiency proxied by CET4 and CET6. In our sample, all students were required under university policy to take and pass CET4 as a condition for attaining an undergraduate degree; however, CET6 was not compulsory for students. As a result, we had 235 students out of 498 in the sample taking the CET6 tests. Based on this, we further divided the sample into those with and without CET6 tests. More testing results are presented in Table 3. It was not easy to find reliable and convincing variables to measure students' English level. CET4 and CET6 scores have been widely used by China's Ministry of Education and universities nationwide to test college students' English proficiency. After controlling the English proficiency level, the association between Score and Bilingual was still statistically insignificant. In addition, we observed that, in a bilingual environment in which textbooks, exercises, and exams use English as a medium, a higher English proficiency level was significantly associated with higher academic performance ( 0.046 and $0.032, p<0.01$, CET4's coefficient in Model (1)). The positive association was consistent with Hamzah et al.'s findings [38], which suggest a significant direct effect of English language proficiency on academic performance. Then, in Model (3), we replace CET with Credit Hours and GPA, the proxies for study load and learning ability, respectively. Ning and Downing [49] reported a positive association between academic performance and learning competence with the effects of supplemental instruction. Consistently, our results showed that learning competence was positively and significantly associated with academic score $(15.890, p<0.01, G P A$ 's coefficient in Model (3)), whereas the association between study load and score was not statistically significant. We then closely examined the data of study load proxied by Credit Hours and found that the deviation in Credit Hours was minor. The study-load for the majority of students in Chinese universities is very standardized, even though the system allows certain flexibility. Many universities in China have unwritten rules that undergraduates should finish their degree in a four-year timeframe. Therefore, a college student's study-load in the same major is similar in each semester. We regressed the models using all the control variables and found GPA was still significantly and positively associated with Score. In Models (5) and (6) in Table 2, despite the insignificant coefficient between CET4/CET6 (The result suggests that GPA was a more powerful variable than CET4 to illustrate the common sense that smart children do well not only in English tests but also in all other subjects. A student with a higher GPA was more likely to perform better in English and have higher scores in bilingual classes.) and Score, the coefficient between GPA and Score was significant. First of all, the answer to RQ3 was supportive because the significant result held between GPA and Score in all models. We would not simply suggest that learning competence is more important than English proficiency in bilingual courses. Back to the sample, the university provides a sound language supporting program to help students gain appropriate academic English skills (More specifically, the sample university has a dedicated English Language Centre as shown in above discussion and the students' CET scores ranked fifth in the Guangdong region.). As a result, the pre-course ELC training adapts the students well to bilingual courses. Linking Cummin's [46] additive bilingualism hypothesis to RQ2, we suggest that the insignificant correlation between CET4/CET6 and Score does not deny the positive role played by English proficiency in a bilingual environment. English proficiency is still an important contributing factor to their success in academic performance as shown in Model (5) in Table 3 of the sensitivity tests. 
Table 2. Main effects.

\begin{tabular}{|c|c|c|c|c|c|c|}
\hline & Model (1) & Model (2) & Model (3) & Model (4) & Model (5) & Model (6) \\
\hline Variable & Score & Score & Score & Score & Score & Score \\
\hline Bilingual & -0.909 & -0.554 & -1.191 & -1.14 & -1.156 & 0.960 \\
\hline Credit Hours & & & -0.016 & & -0.039 & 0.435 \\
\hline GPA & & & $15.890^{* * *}$ & $16.226^{* * *}$ & $16.352 * * *$ & $15.160 * * *$ \\
\hline CET4 & $0.046^{* * *}$ & & & -0.01 & -0.010 & \\
\hline CET6 & & $0.032 * *$ & & & & -0.003 \\
\hline Constant & $53.916^{* * *}$ & $60.844^{* * *}$ & $26.737 * * *$ & $30.304^{* * *}$ & $30.923^{* * *}$ & $17.143^{* * *}$ \\
\hline Observations & 498 & $235^{\#}$ & 498 & 498 & 498 & $235^{\#}$ \\
\hline $\mathrm{R}^{2}$ & 0.048 & 0.022 & 0.480 & 0.481 & 0.482 & 0.399 \\
\hline
\end{tabular}

Robust $t$-statistics in parentheses, ${ }^{* * *} p<0.01,{ }^{* *} p<0.05$; ${ }^{\#}$ We had 235 students in the sample taking the CET6 tests.

\subsection{Sensitivity Tests}

To test RQ2 (Does English proficiency play a fundamental role on students' academic performance in bilingual environment?), we divided our sample into two groups: CET6 Dum $=1$ and 0. In CET6 Dum $=0$, the coefficient between Bilingual and Score was significantly negative $(-3.534, p<0.01$, Bilingual's coefficient in Model (2)). Students in the CET6 Dum $=0$ group failed CET6 or did not have the CET6 exam score and were considered as being less proficient in English proficiency. Therefore, their comprehension of course content in English seemed to be lower compared to the students in L1 classes. This consequently led to lower academic results achieved by bilingual students. Students in the CET6 Dum = 1 were considered as possessing a higher level of English proficiency and their understanding of English content tended to be higher. This enabled them to catch up with their counterparts in the L1 classes and, therefore, we did not observe significant results between Bilingual and Score in Models (1) and (3) in Table 3. Overall, comparing the results in CET6 Dum = 1 and 0 , we confirmed and extended the regression results in Models (2) and (6) from the previous section. We tested the different results within the sample of bilingual classes as reported in Model (5). The significant and positive result for CET4 suggested that English proficiency matters in achieving higher academic scores. Table 3 is presented below to shows the sensitivity test result.

Table 3. English proficiency grouping.

\begin{tabular}{|c|c|c|c|c|c|}
\hline \multirow{3}{*}{ Variable } & Model (1) & Model (2) & Model (3) & Model (4) & Model (5) \\
\hline & Score & Score & Score & Score & Score \\
\hline & CET6 Dum = 1 & CET6 Dum $=0$ & CET6 Dum = 1 & CET6 Dum $=0$ & Bilingual = 1 \\
\hline Bilingual & 0.998 & $-3.534^{* * *}$ & 0.960 & $-3.540 * * *$ & Automatically Omitted \\
\hline Credit Hours & 0.410 & -0.208 & 0.435 & -0.205 & 0.320 \\
\hline GPA & $15.484^{* * *}$ & $16.828^{* * *}$ & $15.160^{* * *}$ & $16.738^{* * *}$ & $14.653 * * *$ \\
\hline CET4 & -0.010 & -0.003 & & & $0.011^{* *}$ \\
\hline CET6 & & & -0.003 & Automatically Omitted & \\
\hline Constant & 20.456 & $31.843 * * *$ & 17.143 & $31.081^{* * *}$ & $16.067 * *$ \\
\hline Observations & 235 & 263 & 235 & 263 & 187 \\
\hline $\mathrm{R}^{2}$ & 0.400 & 0.400 & 0.399 & 0.607 & 0.545 \\
\hline
\end{tabular}

In Table 4, we test the models using different control variables. The undergraduate major is considered to impact academic score, as accounting students in the fundamental accounting courses may show more interest and commitment than students in other majors (Trusty and Ng [64], Tracey and Robbins [65]). Major is a dummy variable of one if students were majoring in accounting and zero otherwise. Consistent with our assumption, Model (1) reported the significant and positive coefficient between Score and Major (4.252, $p<0.01)$. In addition to GPA, GAS and GBS were used as alternative proxies for learning competence (RQ3). GAS was scaled by total subjects' credit so to minimize the impacts of work load, and GBS was calculated by considering the impacts of English proficiency on students' results. Therefore, we dropped Credit Hours in Model (3), and CET4 in Model (4) to 
avoid multicollinearity. Consistent with the main tests, we found no insignificant correlation between Score and Bilingual in Table 4 . The alternative learning competence measures were significantly and positively associated with Score both at the $p<0.01$ level (GAS: 1.471 and GBS: 1.575).

Table 4. Different control variables.

\begin{tabular}{lcccc}
\hline & Model (1) & Model (2) & Model (3) & Model (4) \\
\hline \multicolumn{1}{c}{ Variable } & Score & Score & Score & Score \\
\hline Bilingual & -0.338 & -1.156 & -0.958 & -0.893 \\
Credit Hours & $1.652^{* * *}$ & -0.039 & & -0.181 \\
CET4 & $0.028^{* * *}$ & -0.010 & -0.005 & \\
Major & $4.252^{* * *}$ & & & \\
GPA & & $16.352^{* * *}$ & & \\
GAS & & & $1.471^{* * *}$ & \\
GBS & $22.565^{* * *}$ & $30.923^{* * *}$ & $-34.871^{* * *}$ & $-31.145^{* * *}$ \\
Constant & 498 & 498 & 498 & 498 \\
\hline Observations & 0.225 & 0.482 & 0.455 & 0.443 \\
$\mathrm{R}^{2}$ & & &
\end{tabular}

Robust $t$-statistics in parentheses, ${ }^{* * *} p<0.01,{ }^{* *} p<0.05$.

We then ran regression analyses using different score components, i.e., Score1 and Score2, representing students' examination scores and class performance, respectively, and found an insignificant correlation between Bilingual and different score components in Table 5. Conversely, Dafouz and Camacho [15] reported that the average grade of active participation in EMI classes is not as high as that in non-EMI/L1 classes, but that exam grades in EMI classes tend to be higher. Then, they investigated the comparison further by classifying the grade into low, medium, and high achievers. The content teacher in Dafouz and Camacho [15] claimed that low achievers participate less in classroom discussions, often fail to submit homework exercises, and do not always complete practical exercises on the blackboard when requested. Responding to the contradictory results in class participation, we attributed the insignificant correlation between bilingual dummy and class participation in our sample to the transitional function provided by bilingualism. At the fundamental level, students struggled with brand new concepts and terminology, building sound theoretical frameworks, and academic literacy at the advanced level. Different from EMI, our bilingual lecturer used L1 language simultaneously for content teaching and helped students deal with language obstacles in the learning process. According to Shi [12], bilingual instruction was more acceptable to students than EMI in Chinese HEIs. Consequently, many Chinese universities launch increasingly parallel bilingual programs for students with interest in L2 environment learning. The result of using different dependent variables are presented below in Table 5.

\subsection{Contributions, Limitations, and Future Research}

Based on Cummins threshold hypothesis, we empirically illustrated that students with high L2 competency (additive bilinguals) were likely to enjoy cognitive advantages and overcome language disadvantages to achieve academic benefits. To the best of our knowledge, research on the impact of HEIs' bilingual programs on academic performance is limited and incomplete. As pointed out by Dafouz and Camacho [15], previous research focusing on the language barrier and drawbacks of L2 teaching and learning, called for more effective learning conditions and support facilities for all stakeholders involved. In response, we found that the language barrier to academic performance can be overcome in a setting with favorable and effective language support. Our results also provide empirical evidence to the limited research in the area of bilingual instruction and academic performance at the tertiary level. Considering the immense differences between the Chinese and English language families (Janson [33]), bilingual instruction, instead of EMI, is more appropriate for the Chinese HEIs students. Overall, our findings can enlighten policy makers to consider support at the university level, which will facilitate effective teaching and learning in a bilingual environment. 
Table 5. Different dependent variables.

\begin{tabular}{|c|c|c|c|c|c|c|c|c|}
\hline \multirow{3}{*}{ Variable } & Model (1) & Model (2) & Model (3) & Model (4) & Model (5) & Model (6) & Model (7) & Model (8) \\
\hline & Score1 & Score1 & Score1 & Score1 & Score 2 & Score 2 & Score 2 & Score 2 \\
\hline & \multicolumn{2}{|c|}{ Full sample } & \multicolumn{2}{|c|}{ CET6 Dum $=1$} & \multicolumn{2}{|c|}{ Full Sample } & \multicolumn{2}{|c|}{ CET6 Dum = 1} \\
\hline Bilingual & 0.826 & 0.824 & 1.551 & 1.705 & -1.830 & -1.827 & -1.685 & -1.676 \\
\hline Credit Hours & 0.267 & 0.262 & 0.118 & 0.017 & 0.237 & 0.245 & 0.838 & 0.832 \\
\hline GPA & $5.145^{* * *}$ & $5.252^{* * *}$ & $4.524^{* *}$ & $5.550 * * *$ & $16.652^{* * *}$ & $16.471^{* * *}$ & $17.132^{* * *}$ & $17.396^{* * *}$ \\
\hline CET4 & 0.001 & 0.001 & 0.015 & & $0.030 * *$ & $0.030 * *$ & 0.019 & \\
\hline Major & & -0.271 & & & & 0.459 & & \\
\hline CET6 & & & & -0.008 & & & & 0.014 \\
\hline Constant & $64.466^{* * *}$ & $64.256^{* * *}$ & $62.740^{* * *}$ & $73.221^{* * *}$ & -3.896 & -3.540 & -16.567 & -13.850 \\
\hline Observations & 498 & 498 & 235 & 235 & 498 & 498 & 235 & 235 \\
\hline $\mathrm{R}^{2}$ & 0.101 & 0.101 & 0.059 & 0.056 & 0.328 & 0.328 & 0.313 & 0.312 \\
\hline
\end{tabular}

Robust $t$-statistics in parentheses, ${ }^{* * *} p<0.01,{ }^{* *} p<0.05$. 
This research is among the few that provide evidence that does not support the negative effects of bilingual instruction on students' academic performance. However, a number of limitations are discussed below with suggestions for future research. The first limitation is the proxy for English proficiency. Even though CET4 and CET6 are acknowledged nationwide as standardized tests for Chinese university students' English language ability, specialized English language assessments should be explored for students' academic use. Cummins [39] argued that cognitive/academic language proficiency (CALP) is empirically distinguished from basic interpersonal communicative skills (BICS). The distinction between CALP and BICS is almost universally acknowledged by scholars, educators, and policy makers, and demonstrated in many research papers and books (Cummins [46]). However, research cannot specifically test CALP and BICS, and apply them to the analysis. Future research is recommended to separate CALP and BICS and test their effects individually. Second, there is the issue of research methods. We used multiple regression models to analyze language impacts on students' academic performance. However, supplemental research methods, such as questionnaires, participant interviews, and regular classroom observation can be adopted in future studies. These new tests will produce rich in-depth and analytical information to explain the effects of bilingual instruction. Lastly, further research can be directed at comparing the different impacts of bilingual instruction and EMI. Although bilingual instruction is more popular than EMI in current Chinese HEIs, some top universities in Beijing and Shanghai are offering increasing numbers of EMI courses given the English proficiency of lecturers and students, and the supportive learning environment. This will provide a fresh opportunity to investigate whether learning in bilingual and EMI courses will produce different outcomes.

\section{Conclusions}

Growing numbers of Chinese studies have critically reviewed EMI's role in content-based learning as reported in the booked edited by Zhao and Dixon [31]. Recent research (Guo et al. [29]) shows the benefit of implementing EMI in motivating students' learning of focal subjects. However, research on evaluating the effects of bilingual programs on learners' outcome are inconclusive and limited. To explore this research opportunity, we compared the performance differences between bilingual and L1 classes, and examined language impacts in a non-native English setting. Our study shows that, in addition to the language medium, language proficiency, and learning competence are influential determinants of student performance. The positive impacts of language proficiency on reducing language difficulties and helping students achieve equivalent academic outcomes are also documented by Ardasheva et al. [41]. In their research, they use a large sample of language learners at different English level. Hamzah et al. [42] show a significant direct effect of English proficiency on academic achievement. In short, the study extends on previous studies in the L2 context, and provides fresh evidence of positive association between language proficiency and students' academic achievement in a bilingual environment. Furthermore, we developed models to test the impact of various determinants' and found that learning competence was more decisive than language proficiency in a bilingual environment. This is consistent with studies by Basturkmen and Shackleford [55] and Klaassen [56]'s that used students' academic performance in junior year.

Our work cannot be simply interpreted as denying the importance of English proficiency and ignoring language barriers to students' academic performance. Cummings [40] points out, students with low-level proficiency in both L1 and L2 ("semilingualism"), who fail to interact with their educational environments, may experience certain disadvantages of academic achievement. Failure to recognize the language hindrance and expecting that students can mechanically adjust themselves to a bilingual environment is detrimental to students' comprehension during content-based learning. The sample university's language program is designed to help students overcome language barriers in bilingual classes, and enhance their academic language proficiency and skills. Our findings suggest that learning competence is key to minimizing the impeding effects of bilingual content learning. Different from research on EMI, we found class participation was not weakened in the bilingual instruction process due to the transitional role and bridging function of bilingualism. The findings provide a better 
understanding of bilingual instruction and fresh empirical evidence for the current debate on language instruction and related supporting policy. Given the popularity of using English in Chinese universities (Guo et al. [29]), and a boom of bilingual courses in subject learnings, policy maker need to examine the impact of bilingual education from the perspective of learners. The integration of learning and using language have become more complex today. A well-designed bilingual course is needed to develop the sustainability of the complex practices of bilinguals in functional inter-relationship with the social and academic aspects. Taken together, the research aims to shed light on designing appropriate bilingual programs to support students having a sustainable development in a bilingual environment.

Author Contributions: Conceptualization, T.L. and Y.H.; Formal analysis, T.L.; Investigation, T.L.; Writing-original draft, T.L. and Y.H.; Writing—review \& editing, T.L.

Acknowledgments: The authors would like to acknowledge the support from Guangdong University of Foreign Studies (GDUFS) and Shantou University (STU). The research was funded by Teng Lin's 2019 GDUFS Startup project.

Conflicts of Interest: The authors declare no conflict of interest.

\section{Appendix A}

\begin{tabular}{|c|c|}
\hline Variable & Definition \\
\hline Score & $\begin{array}{l}\text { The comprehensive results including class attendance rate, home assignments, } \\
\text { and paper-based examination result. }\end{array}$ \\
\hline Score1 & The student's paper-based exams result. \\
\hline Score 2 & $\begin{array}{l}\text { The student's class performance score, which is a combination score of class } \\
\text { participation, attendance, and in-class quiz results. }\end{array}$ \\
\hline Bilingual & A dummy variable of one if the course is bilingual and zero if L1. \\
\hline GPA & The grade point average used to measure a student's academic achievement. \\
\hline Credit Hours & $\begin{array}{l}\text { The total study time that students spend on the course during a semester, also used to } \\
\text { measure students' workload. }\end{array}$ \\
\hline GAS & $\begin{array}{l}\text { A modified GPA score used to control workload impact. For example, two students } \\
\text { studying the same course with different workloads receive the same academic result. } \\
\text { The students with higher workload are considered to have higher GAS under its } \\
\text { calculation formula. }\end{array}$ \\
\hline GBS & A modified GPA score to control for the effects of English proficiency. \\
\hline CET4 & $\begin{array}{l}\text { CET } 4 \text { is the basic level of CET. CET stands for China National College English Test, } \\
\text { and is designed to test non-English-Major students' general English ability in listening, } \\
\text { speaking, reading comprehension, and writing. Its purpose is to ensure that students } \\
\text { meet the required English levels specified in the National College English Teaching } \\
\text { Syllabuses (NCETS). CET has been operated in China for more than two decades and } \\
\text { now has a test population of } 18 \text { million people annually (http:/ / www.cet.edu.cn/). }\end{array}$ \\
\hline CET6 & CET 6 is the advanced level of CET. \\
\hline Accounting Major & A dummy variable of one if students major in accounting and zero otherwise. \\
\hline
\end{tabular}

\section{References}

1. Hu, G. English language education in China: Policies, progress, and problems. Lang. Policy 2004, 4, 5-24. [CrossRef]

2. Altbach, P.G.; Knight, J. The internationalization of higher education: Motivations and realities. J. Stud. Int. Educ. 2007, 11, 290-305. [CrossRef]

3. Huang, F. Internationalization of higher education in the developing and emerging countries: A focus on transnational higher education in Asia. J. Stud. Int. Educ. 2007, 11, 421-432. [CrossRef] 
4. Kim, J.; Tatar, B.; Choi, J. Emerging culture of English-medium instruction in Korea: Experiences of Korean and international students. Lang. Intercult. Commun. 2014, 14, 441-459. [CrossRef]

5. Coleman, J.A. English-medium teaching in European higher education. Lang. Teach. 2006, 39, 1-14. [CrossRef]

6. Deem, R.; Mok, K.H.; Lucas, L. Transforming higher education in whose image? Exploring the concept of the 'world-class' university in Europe and Asia. High. Educ. Policy 2008, 21, 83-97. [CrossRef]

7. Costa, F.; Coleman, J.A. A survey of English-medium instruction in Italian higher education. Int. J. Biling. Educ. Biling. 2013, 16, 3-19. [CrossRef]

8. Dobrota, M.; Bulajic, M.; Bornmann, L.; Jeremic, V. A new approach to the QS university ranking using the composite I-distance indicator: Uncertainty and sensitivity analyses. J. Assoc. Inf. Sci. Technol. 2016, 67, 200-211. [CrossRef]

9. Adamson, B. English with Chinese characteristics: China's new curriculum. Asia Pac. J. Educ. 2001, 21, 19-33. [CrossRef]

10. $\mathrm{Hu}, \mathrm{G}$. Recent important developments in secondary English-language teaching in the People's Republic of China. Lang. Cult. Curric. 2002, 15, 30-49. [CrossRef]

11. Jin, L.; Cortazzi, M. English language teaching in China: A bridge to the future. Asia Pac. J. Educ. 2002, 22, 53-64. [CrossRef]

12. Shi, Q. Bridging the gap between English language learning and content-area instruction in Chinese universities. J. Shandong Agric. Adm. Coll. 2016, 33. (In Chinese)

13. Dafouz, E.; Camacho, M.; Urquia, E. 'Surely they can't do as well': A comparison of business students' academic performance in English-medium and Spanish-as-first-language-medium programmes. Lang. Educ. 2014, 28, 223-236. [CrossRef]

14. Fortanet-Gómez, I. CLIL in Higher Education: Towards a Multilingual Language Policy; Multilingual Matters: Bristol, UK, 2013.

15. Dafouz, E.; Camacho-Miñano, M.M. Exploring the impact of English-medium instruction on university student academic achievement: The case of accounting. Eng. Spec. Purp. 2016, 44, 57-67. [CrossRef]

16. Wang, L. Reflections on bilingual teaching in Chinese universities. Manag. Obs. 2007, 2, 21-22. (In Chinese)

17. Sert, N. The language of instruction dilemma in the Turkish context. System 2008, 36, 156-171. [CrossRef]

18. Byun, K.; Chu, H.; Kim, M.; Park, I.; Kim, S.; Jung, J. English-medium teaching in Korean higher education: Policy debates and reality. High. Educ. 2011, 62, 431-449. [CrossRef]

19. Li, W. Problems and suggestions for EMI professional courses. J. Jiamjusi Educ. Inst. 2013, 8, 349-350. (In Chinese)

20. Crawford, I.; Wang, Z. The impact of individual factors on the academic attainment of Chinese and UK students in higher education. Stud. High. Educ. 2015, 40, 902-920. [CrossRef]

21. Van der Walt, C. University students' attitudes towards and experiences of bilingual classrooms. Curr. Issues Lang. Plan. 2006, 7, 359-376. [CrossRef]

22. De Courcy, M. Policy challenges for bilingual and immersion education in Australia: Literacy and language choices for users of aboriginal languages, Auslan and Italian. Int. J. Biling. Educ. Biling. 2005, 8, 178-187. [CrossRef]

23. Yang, W.; Gosling, M. What makes a Taiwan CLIL programme highly recommended or not recommended? Int. J. Biling. Educ. Biling. 2014, 17, 394-409. [CrossRef]

24. Lo, Y.Y.; Lo, E.S.C. A meta-analysis of the effectiveness of English-medium education in Hong Kong. Rev. Educ. Res. 2014, 84, 47-73. [CrossRef]

25. Bergroth, M. Immersion students in the matriculation examination three years after immersion. In Exploring Dual-Focused Education: Integrating Language and Content for Individual and Societal Needs; Bjorklund, S., Mard-Miettinen, K., Bergstrom, M., Sodergard, M., Eds.; Centre for Immersion and Multilingualism, University of Vaasa: Vaasa, Finland, 2006; pp. 123-134.

26. Tong, F.H.; Shi, Q. Chinese-English bilingual education in China: A case study of college science majors. Int. J. Biling. Educ. Biling. 2012, 15, 165-182. [CrossRef]

27. $\mathrm{Hu}, \mathrm{G}$. The craze for English-medium education in china: Driving forces and looming consequences. Engl. Today 2009, 25, 47-54. [CrossRef]

28. Hu, G.; Lei, J. English-medium instruction in Chinese higher education: A case study. High. Educ. 2014, 67, 551-567. [CrossRef] 
29. Guo, H.; Tong, F.; Wang, Z.; Min, Y.; Tang, S. English- vs. Chinese-Medium Instruction in Chinese Higher Education: A Quasi-Experimental Comparison. Sustainability 2018, 10, 4230. [CrossRef]

30. Yan, L.; Xu, H. Ligongke yuanxiao 'hanjie yejinxue' kecheng shuangyu jiaoxue de lilun yu shijian yanjiu [Research on the theory and practice of bilingual teaching in the course of welding metallurgy in scientific universities]. Autom. Instrum. 2015, 1, 209-210. (In Chinese)

31. Zhao, J.; Dixon, L.Q. English-Medium Instruction in Chinese Universities: Perspectives, Discourse and Evaluation; Routledge: New York, NY, USA, 2017.

32. Pérez-Cañado, M.L. CLIL research in Europe: Past, present, and future. Int. J. Biling. Educ. Biling. 2012, 15, 315-341. [CrossRef]

33. Janson, T. The History of Languages: An Introduction; Oxford University Press: New York, NY, USA, 2012.

34. Hu, G.W. The misleading academic discourse on Chinese-English bilingual education in China. Rev. Educ. Res. 2008, 78, 195-231. [CrossRef]

35. Shen, Z.Y. 'Yiyi zai shijian mubiao zai chengxiao' [Significance and objectives of bilingual education]. Zhongguo Jiaoyubao 2004, 2. (In Chinese)

36. Pi, W.B. Zhongxue shuangyu jiaoxue de shijian yu sikao [Bilingual education in secondary schools and reflections]. Master's Thesis, East China Normal University, Shanghai, China, 2004. (In Chinese)

37. Jin, K.; Zhuang, Y.X. 'Shuangyu jiaoxue zheng liaoyuan' [Bilingual education is spreading like a prairie fire]. Jiefang Ribao 2002, 6.

38. Li, M. The effectiveness of a bilingual education program at a Chinese university: A case study of social science majors. Int. J. Biling. Educ. Biling. 2016, 21, 897-912. [CrossRef]

39. Cummins, J. The cross-lingual dimensions of language proficiency: Implications for bilingual education and the optimal age issue. TESOL Q. 1980,14,175. [CrossRef]

40. Cummins, J. Linguistic interdependence and the educational development of bilingual children. Rev. Educ. Res. 1979, 49, 222-251. [CrossRef]

41. Ardasheva, Y.; Tretter, T.R.; Kinny, M. English language learners and academic achievement: Revisiting the threshold hypothesis. Lang. Learn. 2012, 62, 769-812.

42. Hamzah, M.S.; Abdullah, H.; Ahmad, M. Effect of English proficiency on social capital and academic achievement among economic students. Int. J. Bus. Soc. 2015, 16, 453-469.

43. Lin, C.K.; Zhang, J.M. Investigating correspondence between language proficiency standards and academic content standards: A generalizability theory study. Lang. Test. 2014, 31, 413-431. [CrossRef]

44. Dong, C.Y.; Du, C.H. "Shuāng Yǔ Jiāo Xué Xiào Guǒ Hé Xué Shēng Yīng Yǔ Shuǐ Píng Guān Xì Tàn Tăo" Survey on the relationship between bilingual education effectiveness and students' English proficiency. Educ. Teach. Forum 2013, 5, 128-130. (In Chinese)

45. Han, J.; Yu, L. "Wǒ Guó Gāo Xiào Jìn Háng Shuāng Yǔ Jiāo Xué Xué Shēng Xū Jù Bèi De Yīng Yǔ Shuǐ Píng” A study to determine Chinese college students' English proficiency requirement for bilingual education. Mod. Lang. 2007, 30, 65-72. (In Chinese)

46. Cummins, J. Reflections on Cummins (1980), 'the cross-lingual dimensions of language proficiency: Implications for bilingual education and the optimal age issue'. TESOL Q. 2016, 50, 940-944. [CrossRef]

47. Lasagabaster, D.; Sierra, J.M. Language attitudes in CLIL and traditional EFL classes. Int. CLIL Res. J. 2009, 2, 4-17.

48. Merisuo-Storm, T. Development of boys' and girls' literacy skills and learning attitudes in CLIL education. In Exploring Dual-Focused Education: Integrating Language and Content for Individual and Societal Needs; Bjorklund, S., Mard-Miettinen, K., Bergstrom, M., Sodergard, M., Eds.; Centre for Immersion and Multilingualism, University of Vaasa: Vaasa, Finland, 2006; pp. 176-188.

49. Ning, H.K.; Downing, K. The impact of supplemental instruction on learning competence and academic performance. Stud. High. Educ. 2010, 35, 921-939. [CrossRef]

50. Weinstein, C.E.; Palmer, D.R. LASSI User's Manual, 2nd ed.; H \& H Publishing: Clearwater, FL, USA, 2002.

51. Tatzl, D. English-medium masters' programmes at an Austrian university of applied sciences: Attitudes, experiences and challenges. J. Engl. Acad. Purp. 2011, 10, 252-270. [CrossRef]

52. Airey, J.; Linder, C. Language and the experience of learning university physics in Sweden. Eur. J. Phys. 2006, 27, 553-560. [CrossRef]

53. Airey, J. Science, language and Literacy: Case Studies of Learning in Swedish University Physics. Ph.D. Thesis, Faculty of Science and Technology, Acta Universitatis Upsaliensis, Uppsala, Sweden, 2009. 
54. Hellekjaer, G.O. Language Matters: Assessing lecture comprehension in Norwegian English-medium higher education. In Language Use in Content-and-Language-Integrated Learning (CLIL); Dalton-Puffer, C., Nikula, T., Smit, U., Eds.; John Benjamins: Amsterdam, The Netherlands, 2010; pp. 233-258.

55. Basturkmen, H.; Shackleford, N. How content lecturers help students with language: An observational study of language-related episodes in interaction in first year accounting classrooms. Eng. Spec. Purp. 2015, 37, 87-97. [CrossRef]

56. Klaassen, R. The International University Curriculum: Challenges in English-Medium Engineering Education. Ph.D. Thesis, Department of Communication and Education, Delft University of Technology, Delft, The Netherlands, 2001.

57. He, Y. “Duì Jiàn Lì Gāo Xiào Huì Jì Zhuān Yè Shuāng Yǔ Jiāo Xué Tĩ Xì De Sī Kăo” Thoughts on establishing bilingual teaching system in accounting programs in colleges and universities. Educ. Career 2006, 32, 22-24. (In Chinese)

58. Kieso, D.E.; Weygandt, J.J.; Warfield, T.D. Intermediate Accounting, 16th ed.; Wiley: Hoboken, NJ, USA, 2016.

59. Kuteeva, M.; Airey, J. Disciplinary differences in the use of English in higher education: Reflections on recent language policy developments. High. Educ. 2014, 67, 533-549. [CrossRef]

60. Chang, J.-Y.; Kim, W.; Lee, H. A language support program for English-medium instruction courses: Its development and evaluation in an EFL setting. Int. J. Biling. Educ. Biling. 2017, 20, 510-528. [CrossRef]

61. Van der Meer, J.; Jansen, E.; Torenbeek, M. 'It's almost a mindset that teachers need to change': First-year students' need to be inducted into time management. Stud. High. Educ. 2010, 35, 777-791. [CrossRef]

62. Szafran, R.F. The effect of academic load on success for new college students: Is lighter better? Res. High. Educ. 2001, 42, 27-50. [CrossRef]

63. Watzinger-Tharp, J.; Swenson, K.; Mayne, Z. Academic achievement of students in dual language immersion. Int. J. Biling. Educ. Biling. 2016. [CrossRef]

64. Trusty, J.; Ng, K.-M. Longitudinal effects of achievement perceptions on choice of postsecondary major. J. Vocat. Behav. 2000, 57, 123-135. [CrossRef]

65. Tracey, T.J.G.; Robbins, S.B. The Interest-major congruence and college success relation: A longitudinal study. J. Vocat. Behav. 2006, 69, 64-89. [CrossRef] 